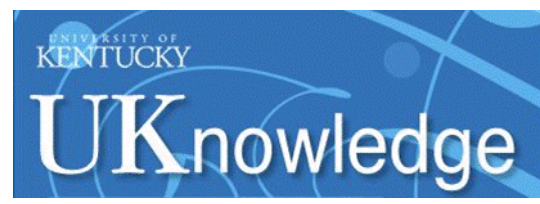

University of Kentucky

UKnowledge

$11-2015$

\title{
Character Strengths in Chinese Philosophies: Relevance to Service Leadership
}

\author{
Daniel T. L. Shek \\ University of Kentucky \\ Rachel C. F. Sun \\ University of Hong Kong, China \\ Ting Ting Liu \\ Wuhan University, China
}

Follow this and additional works at: https://uknowledge.uky.edu/pediatrics_facpub

Part of the Pediatrics Commons

Right click to open a feedback form in a new tab to let us know how this document benefits you.

\section{Repository Citation}

Shek, Daniel T. L.; Sun, Rachel C. F.; and Liu, Ting Ting, "Character Strengths in Chinese Philosophies:

Relevance to Service Leadership" (2015). Pediatrics Faculty Publications. 203.

https://uknowledge.uky.edu/pediatrics_facpub/203

This Article is brought to you for free and open access by the Pediatrics at UKnowledge. It has been accepted for inclusion in Pediatrics Faculty Publications by an authorized administrator of UKnowledge. For more information, please contact UKnowledge@lsv.uky.edu. 


\section{Character Strengths in Chinese Philosophies: Relevance to Service Leadership \\ Digital Object Identifier (DOI) \\ https://doi.org/10.1515/ijdhd-2015-0452}

\section{Notes/Citation Information}

Published in International Journal on Disability and Human Development, v. 14, no. 4, p. 309-318.

(C) 2015 Walter de Gruyter GmbH, Berlin/Boston

The copyright holders have granted the permission for posting the article here. 


\section{Daniel T.L. Shek*, Rachel C.F. Sun and Ting Ting Liu \\ Character strengths in Chinese philosophies: relevance to service leadership}

DOI 10.1515/ijdhd-2015-0452

Received April 17, 2014; accepted June 17, 2014; previously published online September 12, 2015

\begin{abstract}
According to the Hong Kong Institute of Service Leadership and Management, moral character or character strength is an important attribute of an effective service leader. In connection to this, "Character Strengths in Chinese Philosophies" is one of the lecture topics taught in a course titled "Service Leadership" in a university in Hong Kong. Several topics are covered in that lecture. First, the relevance of Chinese philosophies to service leadership is discussed. Second, the core virtues in Confucian thoughts are presented. Third, the relevance of Confucian virtues to service leadership is examined. Finally, conclusions and reflections on the relevance of Confucian virtues to service leadership are outlined. In addition to one warm-up activity at the beginning of the lecture, three major activities are designed for related parts of the content. During the lecture, students are encouraged to reflect on their qualities in terms of Confucian virtues and explore effective ways to promote the development of such virtues.
\end{abstract}

Keywords: character strengths; Chinese philosophies; Confucianism; Confucian virtues; service leadership.

\footnotetext{
*Corresponding author: Daniel T.L. Shek, PhD, FHKPS, BBS, SBS, JP, Chair Professor of Applied Social Sciences, Faculty of Health and Social Sciences, Department of Applied Social Sciences, The Hong Kong Polytechnic University, Room HJ407, Core H, Hunghom, Hong Kong, P.R. China, E-mail: daniel.shek@polyu.edu.hk; Center for Innovative Programs for Adolescents and Families, The Hong Kong Polytechnic University, Hong Kong, P.R. China; Department of Social Work, East China Normal University, Shanghai, P.R. China; Kiang Wu Nursing College of Macau, Macau, P.R. China; and Division of Adolescent Medicine, Kentucky Children's Hospital, University of Kentucky, Lexington, KY, USA Rachel C.F. Sun: Faculty of Education, The University of Hong Kong, Hong Kong, P.R. China

Ting Ting Liu: Department of Sociology, Wuhan University, Wuhan, P.R. China
}

Introduction

According to many theories (e.g. ecological models and sociological perspectives), people are influenced by the social culture they live in. Many theorists argued that the history, cultural traditions and maintenance systems of a society shape the beliefs and behavior of individuals. An individual with cognitive and behavioral capacities usually learns from previous experiences and adapts to the changing environment [1]. With specific reference to China, with a history of over 5,000 years, it has a rich heritage of culture and customs defined by different philosophies that shape the social life patterns of Chinese people by guiding individuals' world views and social behavior [2]. Of the numerous classical Chinese philosophies, Buddhism, Confucianism, and Taoism are the primary ones that have exerted profound influences on traditional and modern Chinese societies [3].

Although Buddhism, Confucianism, and Taoism share some similarities, such as the emphasis on the consciousness of mind, there are distinct differences in their views and assumptions about the world and humans. Basically, Buddhism regards life as full of pains and teaches people to recognize the non-existence of self to avoid suffering. In Confucianism, human nature is intrinsically good and human beings can develop virtues in themselves. As for Taoism, it emphasizes the natural rule of the universe and advocates the importance of harmony with nature $[4,5]$. A huge volume of studies have been conducted to explore how these traditional cultures influence Chinese people's value systems and social conduct [6-8], with leadership as one of the topics that has attracted much research interest. For example, Cheung and Chan studied the philosophical foundations of Hong Kong eminent CEOs via a qualitative approach and found that CEOs in Hong Kong practiced a style of leadership synthesizing doctrines of Confucianism, Taoism and other schools of thoughts [9].

Among these three philosophies, Confucianism is probably the most influential to the Chinese people. As pointed out by Redding, Confucianism is "the most apposite single-word label for the values which govern most of their (Chinese) social behavior" [p. 2, 10]. Confucianism had been adopted as the official philosophy for many dynasties 
of China and was institutionalized and propagated through both official educational systems and the selection process of the government [11]. In contrast to Buddhists and Taoists who seek to withdraw from the real world, the followers of Confucianism advocate actions and interventions [8].

There are three fundamental tenets of Confucianism [12]. First, Confucianism maintains that people are the most important element in a society. As such, interpersonal relationships are a key issue to be addressed. Second, morality is the fundamental standard upon which the appropriateness of individual behavior is based. Third, as human nature is intrinsically good, and human behavior is changeable, everybody can be a perfect man if they receive proper education. In short, the overriding concern of Confucianism is to establish a moral and orderly society where people interact harmoniously [4].

Different personal virtues can be identified in Confucian writings. In their review of Confucian virtues, Shek et al. [13] highlighted 12 Confucian virtues. These include a) eight cardinal virtues - "zhong” (loyalty), "xiao" (filial piety), "ren” (benevolence), "ai" (affection), "xin" (trustworthiness), "yi" (righteousness), "he" (harmony) and "ping" (peace); b) four pillars of the country - "li" (propriety), "yi" (righteousness), "lian" (integrity) and "chi" (shame); and c) five constant virtues - "ren" (benevolence), "yi” (righteousness), "li" (propriety), "zhi” (wisdom) and "xin" (trustworthiness) [13]. These specific virtues form a morality-based philosophical framework that has dominated Chinese culture throughout the past centuries.

Despite the criticisms of Confucianism for its negligence of individual rights and advocacy for feudal hierarchy, its thoughts concerning moral cultivation have been revisited and are valued by many contemporary researchers, particularly in view of the growing moral deterioration and disintegration in the contemporary era $[4,14,15]$. Zhang and Veenhoven [3] even claimed that compared to Buddhism and Taoism, Confucianism could provide us with the most appropriate advice for finding happiness in the modern era. As service leadership as a leadership style emphasizes morality and caring with particular reference to the service-oriented economy, Confucian teachings can certainly offer important insights for promoting service leadership in the Chinese context.

\section{Chinese philosophies and service leadership}

According to Chung, Chinese philosophies served as a philosophical foundation of the service leadership framework
(P. Y. Chung, Unpublished manuscript). It is proposed that an effective service leader has to handle three realms of relationships, including the individual realm (intrapersonal relationship with self), group realm (interpersonal relationships with other individuals and groups) and systems realm (relationship with environment and things that "happen to me"). The three philosophies, including Buddhism, Confucianism and Taoism, can be mapped to those three realms of relationship to provide useful insights for the development of effective service leadership in a particular realm (P. Y. Chung, Unpublished manuscript). With reference to the individual domain, with its core belief that happiness is rooted in the detachment of self from outside relationships and desire, Buddhism can provide insights into optimal intrapersonal intelligence. With reference to the interpersonal domain, Confucianism holds that proper human relationships are the basis of a well-operating society and can therefore serve to optimize interpersonal intelligence. At the systems level, due to its emphasis on the natural order and the harmonious relationship between humans and nature, Taoism can offer insights for service leadership. To summarize, according to the Service Leadership Model, Buddhist, Confucian and Taoist thoughts can be used to understand and develop service leadership in self, others and systems, respectively.

As Confucianism has been recognized as an influential philosophy in different Chinese communities, it is considered to be the most important root of the Chinese culture that service leadership can draw on. The Service Leadership and Management (SLAM) curriculum framework posits that the innate moral institutions and instinctive service propensities that humans evolved during the evolutionary adaptation are necessary to individual fitness and survival of groups (P. Y. Chung, Unpublished manuscript). However, in the industrial age, the goodsfocused thinking and business models had undermined people's innate moral institutions and service tendencies. As the SLAM framework calls for attention to the vital role of moral character in service leadership, Confucianism has much to offer in the realm of moral character. As such, these two areas are intimately related.

By comparing Confucian virtues, character strengths and constructs of positive youth development, Shek et al. [13] identified some commonly shared traits and virtues that are culturally unique, suggesting that Confucian virtues can be adopted as a useful framework to understand and promote positive development of Chinese adolescents, and this framework is also what service leadership educators are committed to. In addition, there is empirical evidence supporting the positive outcomes of Chinese leadership styles, and those related practices are conducive to building 
trust, cooperation, competence and other achievements among followers [16]. In short, the literature suggests that Confucian virtues are of importance in directing people to develop moral reasoning and ethical behavior, which is an essential part of quality service leadership.

To equip university students with essential attributes to be effective service leaders, a pilot general education subject titled "Service Leadership" was offered in the second term of the 2012/13 academic year at The Hong Kong Polytechnic University. Among the 14 2-h lectures in the subject, "Character Strengths in Chinese Philosophies" is discussed in the seventh lecture, and its lecture content, together with the rationale behind the curriculum design and the activities used, is presented in detail in the following sections.

\section{Overview of the lecture}

There are four parts in this 2-h lecture, including: 1) three Chinese philosophies and service leadership;2) core Confucian virtues; 3) importance of Confucian virtues in service leadership; and 4) conclusions and reflections. After taking this lecture, students are expected to 1) recognize the influence of traditional Chinese philosophies on the lives of
Chinese people; 2) understand the meanings of key Confucian virtues; 3) appreciate the important role of Confucian virtues in effective service leadership; and 4) reflect on their own performance in terms of the virtues and explore effective ways to promote the development of these virtues. To facilitate the learning of the students, one warm-up activity is arranged at the beginning of the lecture, and three major activities are designed for the content. Details of the schedule of Lecture Seven can be found in Table 1. In this lecture, although the three Chinese philosophies are all covered, the major focus would primarily be put on Confucianism. The aforementioned 12 core virtues of Confucianism as well as their importance to service leadership are covered in the lecture. Students are also encouraged to recognize and promote their personal development of these virtues to become effective service leaders.

\section{Content of the lecture: warm-up activity: mottos of universities in Hong Kong}

As universities in Hong Kong typically choose their mottos inspired by traditional Chinese wisdom, this warm-up

Table 1: Rundown of the lecture.

\begin{tabular}{|c|c|c|}
\hline Activity & Procedures & Materials \\
\hline 1. Opening ( $5 \mathrm{~min})$ & $\begin{array}{l}\text { Opening: } \\
\text {-Recap Lecture } 6\end{array}$ & Lecture PPT \\
\hline 2. Warm-up activity (5 min) & $\begin{array}{l}\text { "Mottos of Universities in Hong Kong” } \\
\text { Purpose: to draw students' attention to Chinese philosophies and their } \\
\text { influence on today's education. }\end{array}$ & Lecture PPT \\
\hline 3. Lecture (10 min) & Part I: three Chinese philosophies and service leadership & Lecture PPT \\
\hline 4. Role-Play(20 min) & $\begin{array}{l}\text { "Confucianism in Chinese Classic Stories” } \\
\text { Purpose: to facilitate students' understanding of and reflection on the } \\
\text { core virtues of Confucianism. }\end{array}$ & $\begin{array}{l}\text { Lecture PPT } \\
\text { Appendix } 1\end{array}$ \\
\hline 5. Lecture (15 min) & Part II: core Confucian virtues & Lecture PPT \\
\hline 6. Self-reflection Exercise (20 $\mathrm{min})$ & $\begin{array}{l}\text { "Confucian Virtues and I" } \\
\text { Purpose: to facilitate students to reflect on their practice of the virtues } \\
\text { valued in Confucianism. }\end{array}$ & $\begin{array}{l}\text { Lecture PPT } \\
\text { Worksheet } 1\end{array}$ \\
\hline 7. Lecture (10 min) & Part III: importance of Confucian virtues in service leadership & Lecture PPT \\
\hline 8. Group Discussion (15 min) & "A Service Leader with Confucian Virtues" & $\begin{array}{l}\text { Lecture PPT } \\
\text { Worksheet } 1\end{array}$ \\
\hline 9. Lecture (5 min) & $\begin{array}{l}\text { Part IV: conclusion } \\
\text {-Conclude the lecture }\end{array}$ & $\begin{array}{l}\text { Lecture } \\
\text { PPT }\end{array}$ \\
\hline 10. Sharing (5 min) & $\begin{array}{l}\text { Sharing: } \\
\text {-Invite two students to share their thoughts after taking this lecture. }\end{array}$ & \\
\hline
\end{tabular}


activity is intended to draw students' attention to the importance of Chinese philosophies (particularly Confucianism) and their influences on contemporary education. The activity invites students to identify the mottos used by different universities in Hong Kong as well as the underlying meanings.

Students are first asked about the motto of The Hong Kong Polytechnic University and its meaning. The teacher then shows several more mottos and invites the class to guess which one is held by which university. After all the mottos are clarified with the help of the teacher, the activity ends with the highlight on the positive role of Confucianism in contemporary higher education.

\section{Part I: three Chinese philosophies and service leadership}

As introduced above, the three most prominent philosophies in the Chinese culture are Buddhism, Confucianism and Taoism. Buddhists focus on suffering that is inevitable in secular life. They believe that the more we adhere to a belief in a self, the more painful we feel. Therefore, to achieve the utter elimination of suffering and the attainment of complete happiness, people are advised to liberate themselves from a self-centered existence and sensory experience [3]. In contrast to Buddhism, Confucianism stresses the importance of an individual's place in the social hierarchy, advocating the cultivation of virtues through personal and communal endeavor to achieve moral goodness [3, 8]. Finally, Taoism cares more about the relationship between human and nature. It is maintained that there are omnipotent and unchangeable laws of nature ruling all the creatures in the universe including human beings. What people should do is simply following the natural order, integrating with nature and maintaining a harmonious relationship with nature [3]. As noted by Chung, according to their distinct assumptions and emphases, these three philosophies can be applied to the three realms of service leadership by providing insights for service leadership (P. Y. Chung, Unpublished manuscript).

To make the concepts of the three philosophies more accessible, students are first invited to nominate representatives among themselves. The fundamental arguments of the philosophies are then introduced to students one by one. A series of illuminating questions are used to link the theories to issues in real life (e.g. environmental protection) and students' personal experience (e.g. family and social relationship) to help them catch the key points quickly. With regard to the application of the three philosophies to the three realms of service leadership, students are first requested to guess which philosophy matches with which realm, and then the teacher follows up to give more illustration. At the end of this part, the focus on Confucianism in this lecture is emphasized, and the reasons are explained.

\section{Activity 1: Confucianism in Chinese classical stories}

To prepare students for the learning of core Confucian virtues in the next part, several classical stories reflecting certain virtues are selected for them to role-play and discuss (see Appendix 1). The design is mainly based on the consideration that playing the well-known stories would be an effective way to have students engage in exploring and reflecting on the traditionally advocated virtues, which is an ideal warm-up before moving to the theoretical part.

This activity is conducted in several steps. First, each group of students is asked to draw a story from the ones provided in Appendix 1. Second, the teacher requests student groups to role-play the story they have drawn. Third, students are directed to reflect on which virtue is highlighted in each story, whether and to what extent they believe in the virtue and the reasons for their standpoints. Activity 1 is wrapped up by pointing out that there are both positive and negative effects of the virtues.

\section{Part II: core Confucian virtues}

Among the traditional philosophies reviewed, Confucianism and its implications to service leadership is the primary concern of the present lecture. A total of 12 core Confucian virtues are covered, which constitute a moral framework that Chinese leaders can refer to [17-23]. As reviewed by Shek et al., these virtues included the eight cardinal virtues, four pillars of the country and five constant virtues [13]:

1. "Zhong" (loyalty): Translated as loyalty, "zhong" in Confucianism emphasizes conscientiousness (i.e. trying to do one's duty and one's best). By dissecting the Chinese character of "zhong", composing of the “center” ("zhong”) and a "heart” ("xin”), it means one's utmost is to keep one's heart unbiased upon making decisions [22]. It is noticeable that in traditional China, "zhong” was often used to guide a country man's loyalty to the government, asserting that the government acted in people's best interests (just like one's parents) and betrayal of country was not allowed [24].

2. "Xiao" (filial piety): As a unique Confucian teaching, "xiao" means a sense of unconditional duty and 
respect toward one's parents. The Analects defines the ways to show filial piety as that "when one's parents are alive, one serves them in accordance with the rites; when they are dead, one buries them in accordance with the rites and sacrifices to them in accordance with the rites" [23]. Filial piety goes closely with loyalty, as countrymen were educated to be loyal to the government as the way they were filial to their parents, and those showing filial piety to parents were usually found to be filial to their country as well $[22,25]$.

3. "Ren" (benevolence): "Ren" means a sense of the dignity of human life or a feeling of humanness toward others. In other words, it is a concern for the wellbeing of other people [17]. Considered the highest Confucian principle, "ren" represents the essence of man, which is almost equal to "virtue" [3]. It is like a seed from which all the other virtues develop.

4. "Ai" (affection): "Ai" means affection and passion for one's fellow human beings, which is often paired with "ren" in Confucianism. A person with "ai" would take care of their interpersonal relationship with care, respect and humanity [18].

5. "Xin" (trustworthiness): "Xin" refers to a sense of trust or honesty and the ability to keep one's words. It is also interpreted as a belief that a person can be relied upon in times of need, which is based on the generosity, sincerity, kindness, and justice that person displays. "Xin" is considered the foundation upon which meaningful relationships in social life are developed and maintained. It is essential to leadership, through which the individual members are connected, and the leader is able to make decisions for the group [24].

6. "Yi" (righteousness): "Yi" can be simply interpreted as the ability to do the "right" things. "Yi" leads people to observe social orders and moral principles, restrain oneself to resist temptations and sacrifice personal interest to insist on the right way when necessary $[20,21]$. In other words, individuals shall understand the prescriptive rules attached to their social roles, and do whatever their roles demand them to do and not exceed these duties.

7. "He" (harmony): "He" refers to a state that people observe proper rules and social order in order to attain stability [26]. "He" is not against diversity, and on the contrary, it is valued that different people coexist and interact smoothly in a community [26]. The virtue of "he" is central to Confucianism, as harmony is viewed as an ideal state for interpersonal relationship and the whole country. Although it serves the maintenance of social inequality in history, it offers positive implications to the development of healthy social relationships in contemporary society.

8. "Ping" (peace): "Ping" is translated as peace, referring to a quiet state of mind without much thought given to the trivial and mundane details of life. It also denotes a sense of calmness and peace. "Ping" is usually accompanied by "he". While "he" normally involves interpersonal relationships, "ping” can exist either within a person or among a group of people.

9. "Li" (propriety): There are two basic meanings of "li" [19]. First, it can serve as the concrete guide for people to regulate their behaviors properly in various relationships. In the five cardinal relationships, father and son, elder brother and younger brother, husband and wife, older friend and younger friend and ruler and subject are the basic human relationships in a society. Second, it can be understood as the general principle of social order or general ordering of life that steers people toward a moral life.

10. "Lian" (integrity): "Lian" initially refers to a sense of moderation in material and emotion. The concept can further be understood as the ability to distinguish right from wrong as well as a sense of cleanness, honor and integrity. A person with the quality of "lian" would feel a sense of honor when engaging in good conduct, which can promote his/her integrity [22].

11. "Chi" (shame): "Chi" means a sense of shame, which is regarded as a feeling associated with the commitment of immoral behavior. "Chi” is usually accompanied with "lian", both of which involve an emotion and also a capacity that induces one to do right things and avoid misbehaviors in a conscious manner. People led by these virtues are also able to make timely self-reflection and identify the ways of personal cultivation [23].

12. "Zhi" (wisdom): In Confucianism, "zhi" refers to wisdom, especially moral wisdom. Mencius emphasized that people possessing "zhi" can discern right from wrong and good from not good [19]. Therefore, "zhi” is an important virtue prerequisite to conduct and making moral judgments.

Although the 12 Confucian virtues are not strange to most Chinese students, their understanding may be limited. Hence, the teacher should attempt to lead students to critically comprehend the virtues under the current social context and recognize the positive influence of them. The virtues are introduced one by one. Multiple methods are adopted to facilitate the teaching, including metaphors, reflection-provoking questions and discussion on controversial issues. For example, "ren" as the core Confucian virtue is referred to as the seed of other virtues, and 
questions like "Can/Should we love people who committed crime or are in conflict or betrayed us?" are posed to stimulate students' reflection on the meaning of benevolence. As for "yi", students are directed to consider and discuss whether signing attendance in a class for a close friend is a righteous act, and what the right ways are to show righteousness.

\section{Activity 2: Confucian virtues and I}

The second class activity is arranged at the end of Part 2 to introduce a series of virtues. To consolidate students' learning and promote the application of Confucian virtues in their daily lives, a structured self-reflection is designed for this activity (see Appendix 2). The focus is placed on the practice and development of the virtues from students' perspectives.

In this activity, each student is first requested to pick three virtues and reflect on their own practice of them with specific examples. They then are invited to identify the ones that are performed less well and the approaches to promoting them in future. After their completion of the worksheet, the teacher invites several students to share in class and wraps up the activity with a brief summary.

\section{Part III: importance of Confucian virtues in service leadership}

As Confucianism emphasizes morality, Confucian virtues can be understood as character strengths valued in Chinese culture. Although there is growing urbanization and industrialization, it is commonly recognized that these virtues still play an important role in contemporary China $[3,14,27]$. As moral character is an essential part of a service leader, Confucian virtues can directly serve as a guiding framework for people to understand their character strengths that contribute to the development of service leadership in a Chinese context.

Peterson and Seligman proposed a framework on character strengths that includes a wide range of positive personal traits related to personal thoughts, feelings, and behaviors [28]. Compared with Western concepts of character strengths, Confucian virtues have heavier emphases on social relationships and moral qualities, and some virtues are advocated cross-culturally [13]. There are many factors that may influence the formation of character strengths and virtues, including both personal attributes such as genes, life experiences and values, and situational conditions like organizational ethical context, culture and socioeconomic conditions [29]. It is argued that character strengths and positive core moral beliefs, intentions and predispositions would lead a person to behave in a way that is consistent with his/her value system $[29,30]$. When this comes to a service leader, the moral conduct the leader displays can create a positive and virtuous atmosphere that empowers people around to make more efforts toward collective goals. This explains how the moral character of service leaders functions in enabling him/her to boost group performance and foster others' prosperity, which is in contrast to the old leadership pattern in which commands and controls led to passiveness among the subordinates.

With reference to the specific Confucian virtues, empirical evidence shows that they are generally associated with a variety of positive outcomes. For example, benevolent leadership, as opposed to authoritarian style, was found to increase followers' deference and work motivation, thus eliciting more favorable group achievement [31]. Another study suggested that trustworthiness is a condition leading to trust, which is a vital component of relationships and a critical element to organizational success [32]. As for propriety, as it might help to enhance the relatedness, reciprocity and emotional attachment among a group of people, cohesion of the group was strengthened [33]. Other research findings are also available suggesting relationships between a) a leader's wisdom and performance in problem-solving, innovative-thinking and self-reflection [34]; b) a leader's integrity and followers' satisfaction, commitment and productivity [35]; and c) inner harmony and peace of leaders and the security of staff and consensus in group decision-making [36]. In short, as shown in the existing literature, there are multiple paths via which the Confucian virtues can contribute to service leadership qualities.

Flow charts are used in this part to illustrate the formation and functioning mechanisms of character strengths and virtues of service leaders. A brief summary of positive outcomes of Confucian virtues is also provided based on empirical research findings. To give more concrete ideas, several virtues are picked and exemplified for their positive roles in service leadership.

\section{Activity 3: a service leader with Confucian virtues}

Activity 3 is intended to assist students to understand the importance of Confucian virtues to service leadership with 
reference to professional contexts (e.g. hotel manager, social worker, engineer, fashion designer). There are several jobs listed for students to discuss in terms of what Confucian virtues a service leader in that position should possess. The jobs are basically chosen from the majors of the students with the purpose of associating the cultivation of Confucian virtues with their career development.

The steps in this activity are as follows. First, each group is asked to pick a job from the list. Second, the students are requested to discuss in groups which three virtues are the most important to a service leader in that position and why. Third, some groups are invited to present their ideas. Fourth, the activity is wrapped up by highlighting the positive implications of Confucian teachings to professional development.

\section{Part IV: conclusions and reflections}

In the last part of the lecture, students are routinely led to recap key knowledge points, including the basic viewpoints of Buddhism, Confucianism and Taoism, their implications to service leadership and the core Confucian virtues as well as their positive effects. It is also highlighted that leadership must fit within societal culture. Therefore, Confucian teachings should be particularly studied to better know, serve and lead people living in the Chinese culture.

\section{Discussion}

Regarding the present lecture on character strengths and service leadership, some issues can be highlighted. First, given the conceptual and philosophical nature of Confucian virtues, we can consider whether these virtues are measurable. In a classroom setting, we can ask students to design some assessment items for discussion. Second, the resemblance between Confucian concepts and character strengths in Western literature can be a topic for more in-depth investigations. In addition, the issue of whether Western individualistic concepts are compatible with the Confucian collectivistic concepts can be raised. The third issue to be considered is what difficulties would be encountered in the process of self-cultivation. We are living in a world emphasizing flexibility and creativity. Does self-cultivation in terms of self-suppression have any market here? Fourth, although Chung proposed that Buddhism, Confucianism and Taoism can be mapped to the personal, interpersonal and systems domains, respectively, we can argue that these three philosophies are also related primarily to the intrapersonal domain. Finally, it would be interesting to ask how the internalization of Confucian values in students can promote their mental health and leadership qualities. This question is important because there are research findings showing that there are developmental issues confronting Chinese university students in Hong Kong [37, 38]. 


\title{
Appendix 1
}

\author{
THE HONG KONG POLYTECHNIC UNIVERSITY \\ DEPARTMENT OF APPLIED SOCIAL SCIENCES \\ APSS2820 Service Leadership
}

Lecture Seven: Character Strengths in Chinese Philosophies

\section{Confucianism in Chinese Classical Stories}
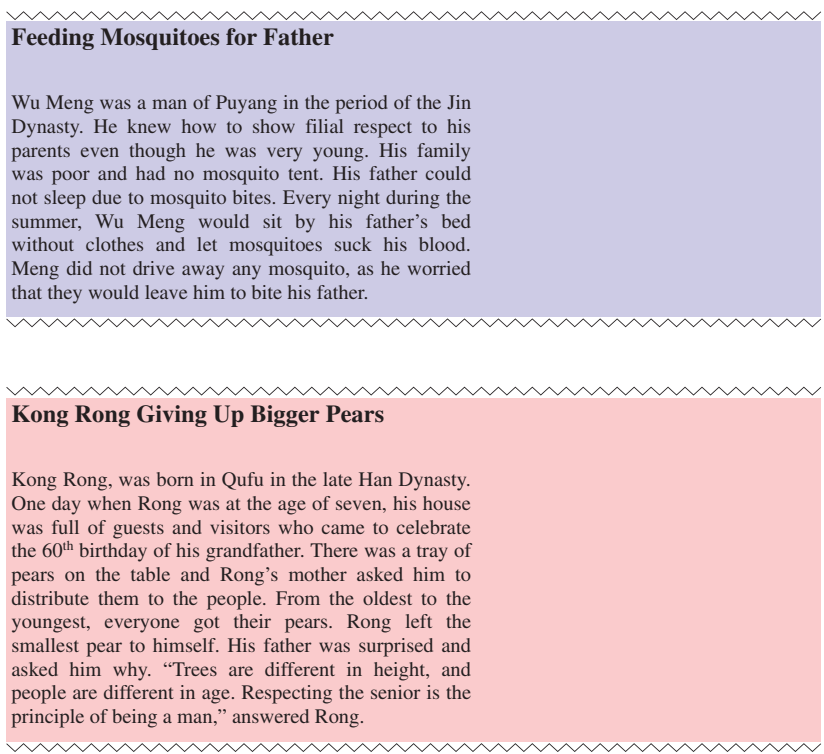

Guan Yu Releasing Cao Cao

Cao Cao's troops had suffered heavy casualties in the Chibi Campaign. An army headed by Guan Yu stormed out to block the way of Cao Cao. At the sight of Guan Yu's mighty force, the hopel Cao had to beg Guan Yu for a way out. "Now I am pressed in the corner. Please have mercy on me for our past friendship and let me go. Do you remember you killed six of my generals when you passed through the five passes?"' In his mind, Guan Yu admitted that if Cao Cao did not order his men to let Guan Yu pass through, he would not have survived even if he got through the five passes alive. Guan Yu then ordered his men to five passes Cao Cao to pass through. Thus, Cao Cao made it through alive.

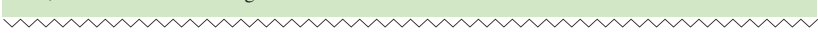

\section{Zengzi Slaughtering a Pig}

Zengzi's wife had to go to the market. The little son insisted on going with her, making a tearful scene. "Stay at home," she said to the boy. "When I come back, I will slaughter a pig for you." When she came back, Zengzi got ready to slaughter the pig. His wife ched him gand s. "I was just kidding." "A child stopped ming a child is "I "A child does not know much and cannot judge for himself. He learns from his parents and listens to what they say. To lie to him is to teach him to lie to others. If a mother lies to her son, he will not trust her anymore. How is she then to educate him?" Then Zengzi went to slaughter the pig and prepared a good meal for their son. 


\section{Appendix 2}

\section{THE HONG KONG POLYTECHNIC UNIVERSITY DEPARTMENT OF APPLIED SOCIAL SCIENCES APSS2820 Service Leadership}

Lecture Seven: Character Strengths in Chinese Philosophies

\section{Confucian Virtues and I}

Referring to the core virtues of Confucianism you've just learned, please reflect on your own practice of these virtues by answering the following three questions.

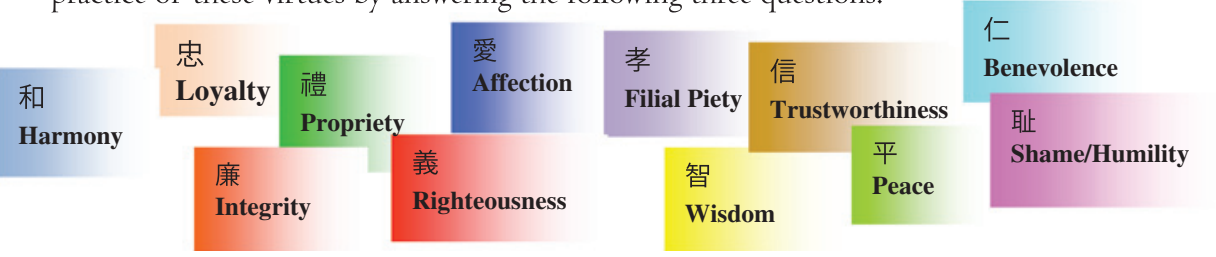

I. Which three virtues do you think you practice best? Give a personal example each to illustrate how these virtues are upheld in your life.

1)

2)

3)

2. Which virtue(s) do you want to promote most? Why?

3. What would you do to further develop the virtue(s)?

\section{References}

1. Whiting BB. Culture and social behavior: a model for the development of social behavior. Ethos 1980;8:95-116.

2. Singelis TM, Brown WJ. Culture, self, and collectivist communication linking culture to individual behavior. Hum Commun Res 1995;21:354-89.

3. Zhang G, Veenhoven R. Ancient Chinese philosophical advice: can it help us find happiness today? J Happiness Stud 2008;9:425-43.

4. Wong KC. Chinese culture and leadership. Int J Leadership Educ 2001;4:309-19.

5. Chan WT. A source book in Chinese philosophy (trans. and comp.). Princeton, NJ: Princeton University Press, 1963.

6. Kirkbride PS, Tang SF, Westwood RI. Chinese conflict preferences and negotiating behaviour: cultural and psychological influences. Organ Stud 1991;12:365-86.

7. Bond MH. Emotions and their expression in Chinese culture. J Nonverbal Behav 1993;17:245-62.

8. Pun KF, Chin KS, Lau H. A review of the Chinese cultural influences on Chinese enterprise management. Int J Manage Rev 2000;2:325-38.
9. Cheung CK, Chan ACF. Philosophical foundations of eminent Hong Kong Chinese CEOs' leadership. J Bus Ethics 2005;60: 47-62.

10. Redding SG. The spirit of Chinese capitalism. Berlin: Walter de Gruyter, 1993.

11. Yum JO. The impact of Confucianism on interpersonal relationships and communication patterns in East Asia. Commun Monogr 1988;55:374-88.

12. Su D, Zhang Y, Hulpke JF. A management culture revolution for the new century? J Appl Manage Stud 1998;7:135-8.

13. Shek DT, Yu L, Fu X. Confucian virtues and Chinese adolescent development: a conceptual review. Int J Adolesc Med Health 2013;25:335-44. Epub ahead of print 27 Mar 2013. DOI: 10.1515/ijamh-2013-0031.

14. Romar EJ. Virtue is good business: confucianism as a practical business ethics. J Bus Ethic 2002;38:119-31.

15. Lee TY, Shek DT, Kwong WM. Chinese approaches to understanding and building resilience in at-risk children and adolescents. Child Adolesc Psychiatr Clin North Am 2007;16:377-92.

16. Cheung CK, Chan AC. Benefits of Hong Kong Chinese CEOs' Confucian and Daoist leadership styles. Leadership Organ Dev J 2008;29:474-503. 
17. Chinese Text Project. Analects: Yan Yuan. Available at: http://ctext.org/analects/yan-yuan. Accessed: 17 Jul 2013.

18. Chinese Text Project. Mencius: Jin Xin I. Available at: http://ctext.org/mengzi/jin-xin-i. Accessed: 17 Jul 2013.

19. Zhang D. Key concepts in Chinese philosophy. New Haven, CT: Yale University Press, 2002.

20. McCormick RM. The Confucian nichiren part 2: Confucian virtues and the mandate of heaven. Available at: http:// nichirenscoffeehouse.net/Ryuei/RAR22.html. Accessed: 17 Jul 2013.

21. Chen LF. The Confucian way: a new and systematic study of "The Four Books". London: Routledge \& Kegan Paul, 1986.

22. Li L. Sang jia gou: wo du lun yu [In Chinese]. Shanxi: Shanxi People's Publisher; 2007.

23. Chinese Text Project. Analects: Wei Zheng. 2006. Available at: http://ctext.org/analects/wei-zheng. Accessed: 18 Jul 2013.

24. Ackerman D, Hu J, Wei L. Confucius, cars, and big government: impact of government involvement in business on consumer perceptions under Confucianism. J Bus Ethics 2009;88:473-82.

25. Project CT. Analects: Xue Er. Available at: http://ctext.org/analects/xue-er. Accessed: 22 Jul 2013.

26. Fernandez JA. The gentleman's code of Confucius: leadership by values. Organ Dyn 2004;33:21-31.

27. Shek DT. Chinese cultural beliefs about adversity: its relationship to psychological well-being, school adjustment and problem behaviour in Hong Kong adolescents with and without economic disadvantage. Childhood 2004;11:63-80.
28. Peterson C, Seligman ME. Character strengths and virtues: a handbook and classification. Washington, DC: Oxford University Press, 2004.

29. Sosik JJ, Cameron JC. Character and authentic transformational leadership behavior: expanding the ascetic self toward others. Consult Psychol J Pract Res 2010;62:251.

30. Bardi A, Schwartz SH. Values and behavior: strength and structure of relations. Pers Soc Psychol B 2003;29:1207-20.

31. Niu CP, Wang AC, Cheng BS. Effectiveness of a moral and benevolent leader: probing the interactions of the dimensions of paternalistic leadership. Asian J Soc Psychol 2009;12:32-9.

32. Caldwell C, Clapham SE. Organizational trustworthiness: an international perspective. J Bus Ethics 2003;47:349-64.

33. Mei-Hui YM. Gifts, favors, and banquets: the art of social relationships in China. Ithaca: Cornell University Press, 1994.

34. Sternberg RJ. WICS: a model of educational leadership. Educ Forum 2004;68:108-14.

35. Rozuel C, Kakabadse N. Ethics, spirituality and self: managerial perspective and leadership implications. Bus Ethics Eur Rev 2010;19:423-36.

36. Perry L. Leadership as harmonization. Asian Philos 2011;21:291-301.

37. Shek DT. Nurturing holistic development of university students in Hong Kong: where are we and where should we go? ScientificWorldJournal 2010;10:563-75.

38. Shek DT, Wong KK. Do adolescent developmental issues disappear overnight? Reflections about holistic development in university students. ScientificWorldJournal 2011;11:353-61. 